Marta Jagusiak-Kocik ${ }^{1}$, Krzysztof Knop ${ }^{2}$

\title{
WYKORZYSTANIE WYBRANYCH NARZĘDZI ZARZĄDZANIA JAKOŚCIĄ I METODY FMEA WPRZEDSIĘBIORSTWIE PRODUKUJĄCYM KONSTRUKCJE SPAWANE DLA MASZYN
}

\begin{abstract}
Streszczenie: W rozdziale zaprezentowano przedsiębiorstwo produkujące konstrukcje spawane dla maszyn, m.in. wysięgniki. Krótko przedstawiono wysięgnik oraz jego proces wytwórczy. W części badawczej zaprezentowano użycie dwóch tradycyjnych narzędzi zarządzania jakością: diagramu Ishikawy i diagramu Pareto-Lorenza. Diagram Ishikawy zastosowano w celu identyfikacji grup przyczyn mogących wpływać na niezgodności wysięgnika, natomiast diagram Pareto-Lorenza stworzono, aby zbadać, które niezgodności wysięgnika występują najczęściej i które należy wyeliminować w pierwszej kolejności. W części badawczej zaprezentowano również praktyczne zastosowanie metody FMEA, za pomocą której zidentyfikowano potencjalne niezgodności wysięgników, a także określono liczby priorytetowe i zaproponowano działania zapobiegawcze i korygujące.
\end{abstract}

Słowa kluczowe: konstrukcje spawane dla maszyn, wysięgnik, diagram Ishikawy, diagram Pareto-Lorenza, metoda FMEA

\section{Wstęp, prezentacja podmiotu i przedmiotu badań}

W dziedzinie zarządzania jakością istnieje wiele metod, technik i narzędzi, które spełniają szereg funkcji w dążeniu do wyeliminowania problemów i poprawy jakości. Wyróżnia się 7 narzędzi tradycyjnych zarządzania jakością i 7 nowoczesnych narzędzi zarządzania jakością oraz 5 metod zarządzania jakością. Narzędzia tradycyjne umożliwiają m.in. identyfikację problemów i ich hierarchizację, jak również kontrolę nad zmiennością procesu i tak, jak np. diagram Ishikawy, przedstawione

${ }^{1}$ dr inż., Politechnika Częstochowska, Wydział Zarządzania, Instytut Inżynierii Produkcji, e-mail: m.jagusiak-kocik@o2.pl

${ }^{2}$ mgr inż., Politechnika Częstochowska, Wydział Zarządzania, Instytut Inżynierii Produkcji, e-mail: kknop@poczta.fm 
są w formie prostego diagramu. Formę prostych graficznych narzędzi przybierają również nowe narzędzia zarządzania jakością, natomiast metody zarządzania jakością są pojęciami bardziej skomplikowanymi, złożonymi, obejmującymi całość analizowanego zagadnienia.

Badane przedsiębiorstwo zajmuje się produkcją konstrukcji spawanych dla maszyn, m.in. ram jezdnych i nośnych maszyn budowlanych oraz transportowych, skrzyni ładunkowych i wysięgników oraz innych elementów nośnych dźwigni. Produkcja przeznaczona jest branż przemysłu górniczego, budowlanego i drogowego. Przedmiotem analizy jest wysięgnik, który stosowany jest w maszynach do wiercenia otworów w skałach. Poprzez zastosowanie nowoczesnych technologii, maszyna $\mathrm{z}$ takim wysięgnikiem jest $\mathrm{w}$ stanie wywiercić otwór głębokości $29 \mathrm{~m}$. Proces wytwórczy wysięgnika związany jest w pierwszej kolejności z oczyszczeniem materiałów hutniczych, następnie materiały te są cięte za pomocą piły taśmowej, ukosowane $\mathrm{z}$ wykorzystaniem palnika ręcznego i szlifowane. Kolejnym elementem procesu wytwórczego jest gięcie materiałów i prostowanie. Po tych etapach następuje składanie i sczepianie elementów za pomocą przyrządów wykonanych pod konkretny wymiar i spawanie przy użyciu półautomatów spawalniczych lub robota spawalniczego. Następnie odbywa się oczyszczanie po spawaniu, obróbka skrawaniem powierzchni, które ważne są z punktu widzenia tolerancji. W oczyszczarce komorowej odbywa się czyszczenie wyrobu, po tej operacji wyrób jest odtłuszczany, malowany w komorze malarskiej i suszony w suszarce komorowej. Gotowy wyrób poddawany jest kontroli, po czym następuje jego magazynowanie.

\section{Identyfikacja grup przyczyn niezgodności przy produkcji wysięgników przy użyciu diagramu Ishikawy}

Diagram Ishikawy (BORKOwSKI S. 2004, BORKOWSKI S., 2012, HAMrol A. 2008, INGALDI M., JAGUSIAK-KoCIK M. 2014, JAGUSIAKKOCIK M., KNOP K. 2015) przypominający swoim kształtem rybią ość, jako jedno z 7 tradycyjnych narzędzi zarządzania jakością, umożliwia zidentyfikowanie grup przyczyn wpływających na dany problem. 
Pomocne w identyfikacji są grupy przyczyn, pogrupowane według określonych zasad:

- $5 \mathrm{M}$ (człowiek, maszyna, materiał, zarządzanie, metoda),

- $5 \mathrm{M}+1 \mathrm{E}(5 \mathrm{M}+$ środowisko $)$,

- $7 \mathrm{M}(5 \mathrm{M}+1 \mathrm{E}+$ pomiar $)$

- i $8 \mathrm{M}(7 \mathrm{M}+$ pieniądze $)$.

Burza mózgów, przeprowadzana w przedsiębiorstwie wśród pracowników z różnych działów pozwala spojrzeć na określony problem z wielu stron i wyodrębnić wiele przyczyn na niego wpływających.

W badanym przedsiębiorstwie za pomocą diagramu Ishikawy dokonano próby zidentyfikowania przyczyn mogących wpływać na niezgodności wysięgnika. W wyniku burzy mózgów zidentyfikowano 7 grup przyczyn, które $\mathrm{w}$ największym stopniu mogą wpływać na niezgodności analizowanego wyrobu - wysięgnika. Grupy te to:

- człowiek,

- maszyna,

- materiał,

- zarządzanie,

- metoda,

- środowisko,

- pomiar.

Na rysunku 1 zaprezentowano diagram Ishikawy dla wymienionych grup przyczyn mogących mieć wpływ na niezgodności wysięgnika. 
Zeszyty Naukowe

Quality. Production. Improvement

$\mathrm{Nr} 1(4)$

2016

s. $54-65$

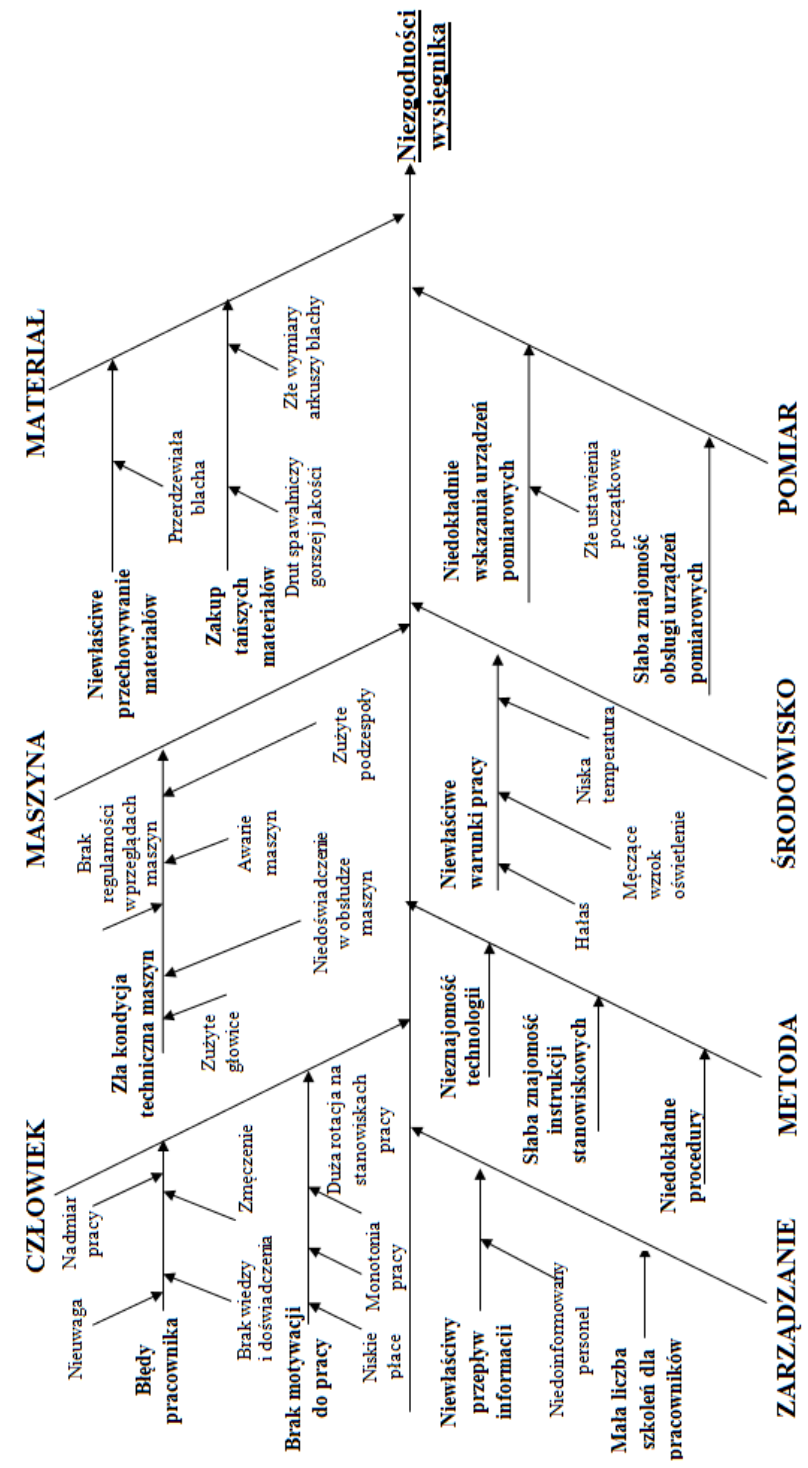

Rys. 1. Diagram Ishikawy dla niezgodności wysięgnika.

Źródto: opracowanie własne 


\section{Hierarchizacja niezgodności wysięgników za pomocą diagramu Pareto-Lorenza}

Kolejną częścią analizy jest hierarchizacja niezgodności analizowanego wyrobu - wysięgnika, przy użyciu diagramu ParetoLorenza (BORKOWSKI S. 2004, BORKOWSKI S., 2012, HAMROL A. 2008, INGALDI M., JAGUSIAK-KOCIK M. 2014, INGALDI M., ROSAK-SZYROCKA J., JAGUSIAK-KOCIK 2012, JAGUSIAK-KOCIK M., KNOP K. 2015, KNOP K., Jagusiak M., StasiaK-BetLejewska R. 2009). Diagram ten pozwala stwierdzić, które niezgodności występują w badanym okresie badawczym najczęściej, lub są powodem największych strat i które powinny zostać wyeliminowane w pierwszej kolejności. Diagram ParetoLorenza bazuje na zasadzie „20-80”, co oznacza, że zazwyczaj niewielka liczba przyczyn (od 20 do 30\%) odpowiada w znacznej części (od 70 do $80 \%)$ za zaistniały skutek. W badanym przedsiębiorstwie, analizę przeprowadzono $\mathrm{w}$ okresie badawczym wynoszącym 1 rok, na hali produkcyjnej, podczas kontroli końcowej wysięgników. Po badaniach stwierdzono występowanie następujących niezgodności wysięgników:

- brak otworu w wysięgniku,

- niedokładny (nierówny) spaw,

- odpadająca powłoka lakiernicza,

- nierówności w powłoce lakierniczej,

- zły wymiar wysięgnika,

- niedomalowana powierzchnia wysięgnika,

- użycie złych gwintów,

- brak określonego elementu w wysięgniku,

- szczeliny w spoinie,

- symetria poza ustaloną tolerancją.

Niezgodności te, na potrzeby diagramu Pareto-Lorenza, oznaczono symbolami od $\mathrm{N}_{1}$ do $\mathrm{N}_{10}$ oraz dokonano ich uszeregowania w kolejności od najczęściej występujących do najrzadziej występujących. Występujące niezgodności wraz z przyjętymi symbolami oraz częstością ich występowania (po uszeregowaniu) prezentuje tablica 1. 
Tablica 1. Struktura niezgodności wysięgników w badanym okresie

\begin{tabular}{|c|c|c|}
\hline $\begin{array}{c}\text { Oznaczenie } \\
\text { niezgodności }\end{array}$ & Nazwa niezgodności & $\begin{array}{c}\text { Uszeregowanie } \\
\text { niezgodności } \\
\text { (szt.) }\end{array}$ \\
\hline \hline $\mathrm{N}_{2}$ & niedokładny (nierówny) spaw & 225 \\
\hline $\mathrm{N}_{3}$ & odpadająca powłoka lakiernicza & 209 \\
\hline $\mathrm{N}_{4}$ & nierówności w powłoce lakierniczej & 65 \\
\hline $\mathrm{N}_{8}$ & brak określonego elementu w wysięgniku & 48 \\
\hline $\mathrm{N}_{6}$ & niedomalowana powierzchnia wysięgnika & 33 \\
\hline $\mathrm{N}_{10}$ & symetria poza ustaloną tolerancją & 21 \\
\hline $\mathrm{N}_{1}$ & brak otworu w wysięgniku & 10 \\
\hline $\mathrm{N}_{7}$ & użycie złych gwintów & 7 \\
\hline $\mathrm{N}_{9}$ & szczeliny w spoinie & 4 \\
\hline $\mathrm{N}_{5}$ & zły wymiar wysięgnika & 2 \\
\hline
\end{tabular}

Źródto: opracowanie własne

Tablica 2. Udzial procentowy i udzial skumulowany niezgodności wysięgników

\begin{tabular}{|c|c|c|c|}
\hline $\begin{array}{c}\text { Oznaczenie } \\
\text { niezgodności }\end{array}$ & Nazwa niezgodności & $\begin{array}{c}\text { Udzial } \\
\text { procentow } \\
\mathbf{y}\end{array}$ & \begin{tabular}{|c|} 
Udzial \\
skumulowan \\
$\mathbf{y}$ \\
niezgodności
\end{tabular} \\
\hline $\mathrm{N}_{2}$ & niedokładny (nierówny) spaw & 36,06 & 36,06 \\
\hline $\mathrm{N}_{3}$ & odpadająca powłoka lakiernicza & 33,49 & 69,55 \\
\hline $\mathrm{N}_{4}$ & nierówności w powłoce lakierniczej & 10,42 & 79,97 \\
\hline $\mathrm{N}_{8}$ & $\begin{array}{l}\text { brak określonego elementu w } \\
\text { wysięgniku }\end{array}$ & 7,69 & 87,66 \\
\hline $\mathrm{N}_{6}$ & $\begin{array}{l}\text { niedomalowana powierzchnia } \\
\text { wysięgnika }\end{array}$ & 5,29 & 92,95 \\
\hline $\mathrm{N}_{10}$ & symetria poza ustaloną tolerancją & 3,37 & 96,31 \\
\hline $\mathrm{N}_{1}$ & brak otworu w wysięgniku & 1,60 & 97,92 \\
\hline $\mathrm{N}_{7}$ & użycie złych gwintów & 1,12 & 99,04 \\
\hline $\mathrm{N}_{9}$ & szczeliny w spoinie & 0,64 & 99,68 \\
\hline $\mathrm{N}_{5}$ & zły wymiar wysięgnika & 0,32 & 100,00 \\
\hline
\end{tabular}

Źródto: opracowanie własne 
Procentowy udział oraz skumulowany udział procentowy niezgodności wysięgników przedstawiono natomiast w tablicy 2 .

Na podstawie danych, które przedstawione są w tablicy 2, stworzono diagram Pareto - Lorenza, przedstawiony na rysunku 2.

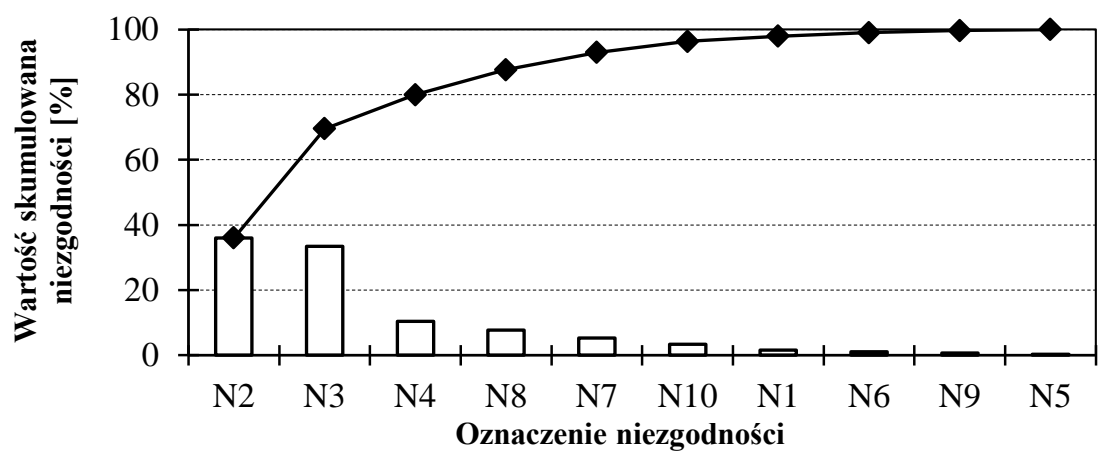

Rys. 2. Diagram Pareto-Lorenza dla analizy niezgodności wysięgników.

Źródlo: opracowanie wtasne

$\mathrm{Z}$ diagramu przedstawionego na rysunku 2 wynika, że $20 \%$ przyczyn powoduje $69,55 \%$ skutków. Ponadto można stwierdzić, że za $69,55 \%$ niezgodności wysięgników 2 niezgodności: niedokładny (nierówny) spaw $\left(\mathrm{N}_{2}\right)$ oraz odpadająca powłoka lakiernicza $\left(\mathrm{N}_{3}\right)$. Pozostałe 8 niezgodności odpowiada za $30,45 \%$ skutków.

\section{Analiza przyczyn i skutków niezgodności wysięgników przy zastosowaniu metody FMEA}

Metoda FMEA (JAgUSIAK-KociK M., KNOP K. 2015, KNOP K., JAGUSIAK M., STASIAK-BETLEJEWSKA R. 2009) polega na wskazaniu oraz ocenie ryzyka, które związane jest ze słabymi punktami mogącymi występować w czasie np. planowania czy produkowania wyrobu. Celem tej metody jest systematyczne identyfikowanie potencjalnych niezgodności wyrobu lub procesu, a następnie ich eliminowanie lub minimalizowanie ryzyka $\mathrm{z}$ nimi związanego. Poprzez metodę FMEA 
Zeszyty Naukowe

$\operatorname{Nr} 1(4)$

Quality. Production. Improvement

możliwe jest doskonalenie wyrobu lub procesu poprzez poddawanie go kolejnym analizom i na podstawie uzyskanych wyników wprowadzanie ulepszeń.

Analiza metody FMEA niezgodności wysięgników w badanym przedsiębiorstwie została przedstawiona w tablicy 3 .

Tablica 3. Arkusz FMEA dla niezgodności wysięgników

\begin{tabular}{|c|c|c|c|c|c|}
\hline ي ص ص & นึ้ & ๙ & ఫิ & $\stackrel{\infty}{+}$ & $i$ \\
\hline N & 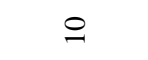 & + & n & + & 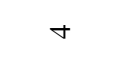 \\
\hline 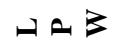 & in & 0 & 0 & $m$ & $m$ \\
\hline$\mu A 0$ & $n$ & $\theta$ & $\theta$ & t & 6 \\
\hline 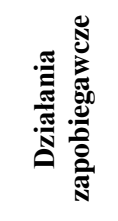 & 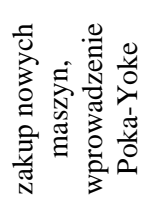 & 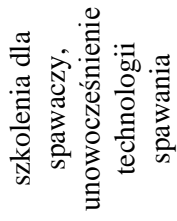 & 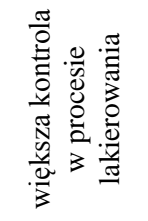 & 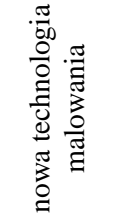 & 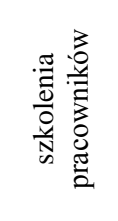 \\
\hline 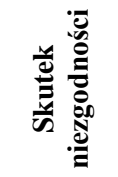 & 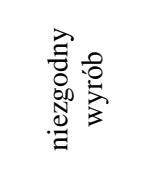 & 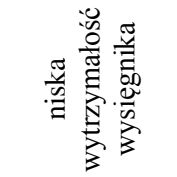 & 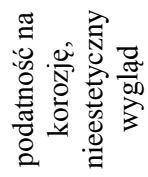 & 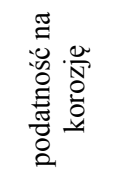 & 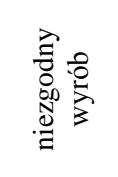 \\
\hline 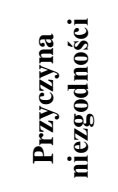 & 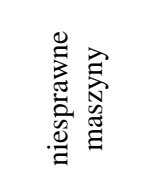 & 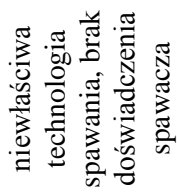 & 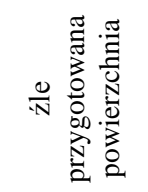 & 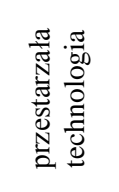 & 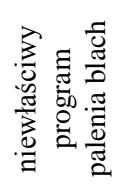 \\
\hline 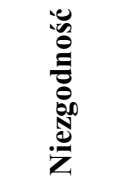 & 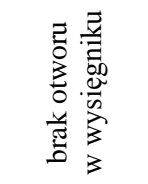 & 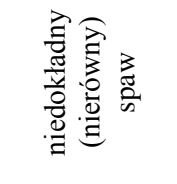 & 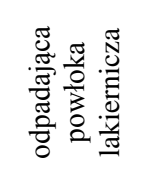 & 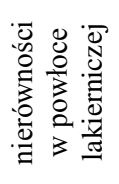 & 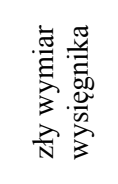 \\
\hline$\dot{i}$ & $\bar{z}$ & $\tilde{z}$ & $z$ & $\vec{z}$ & $z^{\prime \prime}$ \\
\hline
\end{tabular}


Zeszyty Naukowe

$\mathrm{Nr} 1(4)$

Quality. Production. Improvement

\begin{tabular}{|c|c|c|c|c|c|}
\hline ي ش ــ & in & \&్ల & $\cong$ & $\frac{n}{m}$ & $\cong$ \\
\hline NA N & n & ㅇ & $\infty$ & $a$ & $\infty$ \\
\hline 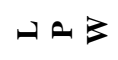 & n & 0 & $ナ$ & $n$ & $r$ \\
\hline OA & 6 & n & 6 & $r$ & $\mathrm{~N}$ \\
\hline 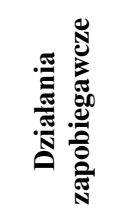 & 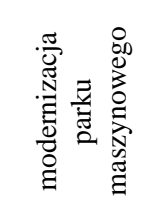 & 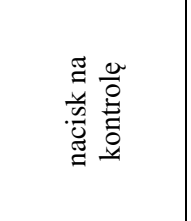 & 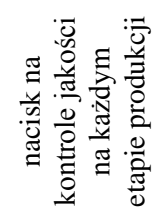 & 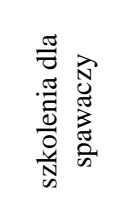 & 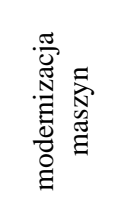 \\
\hline 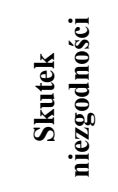 & 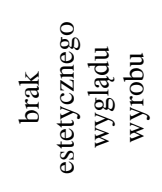 & 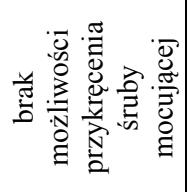 & 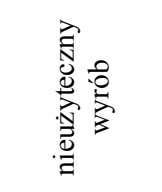 & 总兽 & 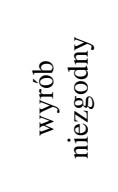 \\
\hline 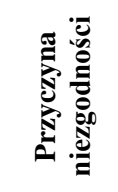 & 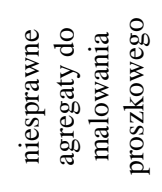 & 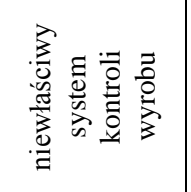 & 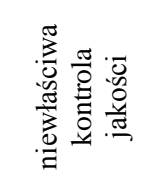 & 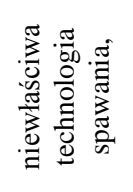 & 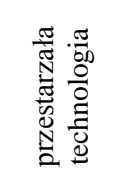 \\
\hline 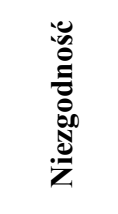 & 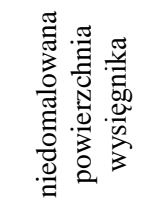 & 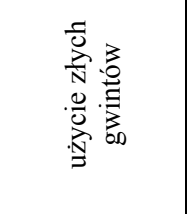 & 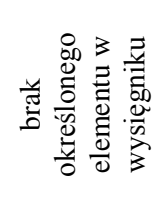 & 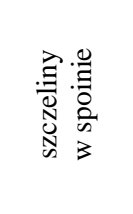 & 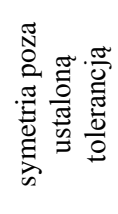 \\
\hline$\dot{\leftrightarrow}$ & $\not ゚$ & $\mathbf{z}$ & $z^{\infty}$ & $z$ & $\stackrel{\varrho}{z}$ \\
\hline
\end{tabular}

Źródto: opracowanie własne 
Kierując się danymi zawartymi w tablicy 3 dla poszczególnych niezgodności wysięgników, stworzono graficzne zestawienie dotyczące Liczby Priorytetowej Ryzyka, które zostało zaprezentowane na rysunku 5.3.

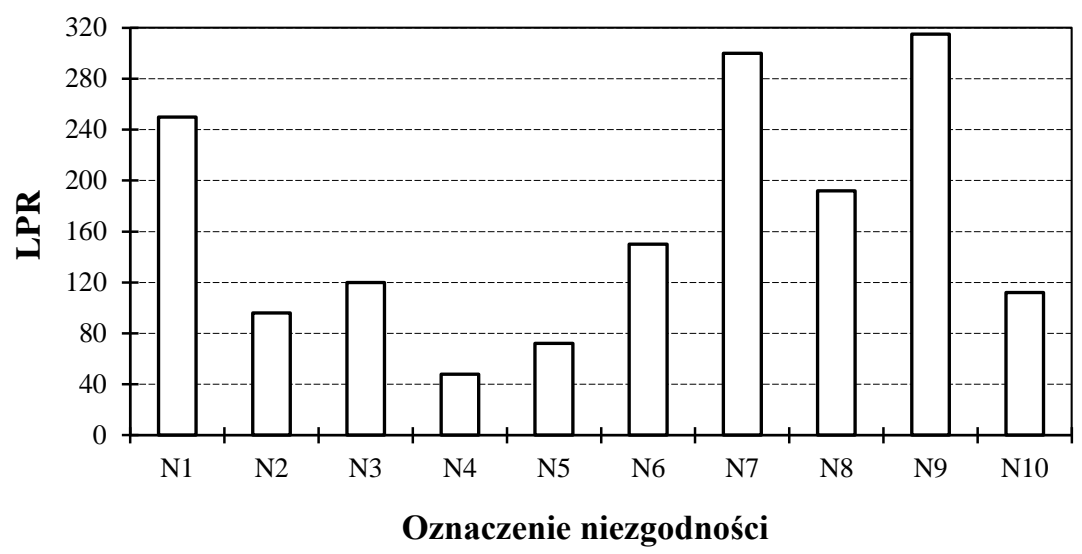

Rys. 3. Graficzna interpretacja LPR dla niezgodności wysięgników

Źródło: opracowanie własne

Na podstawie analizy arkusza FMEA, zaprezentowanego w tablicy 3 oraz na podstawie graficznej interpretacji Liczby Priorytetowej Ryzyka zaprezentowanej na rysunku 3 zauważa się, ze niezgodności: szczeliny w spoinie $\left(\mathrm{N}_{9}\right)$, użycie złych gwintów $\left(\mathrm{N}_{7}\right)$ oraz brak otworu w wysięgniku $\left(\mathrm{N}_{1}\right)$, po analizie Liczb Priorytetowych Występowania, Odkrycia i Znaczenia, uzyskały najwyższe wartości Liczb Priorytetowych Ryzyka. Wynik ten wskazał, gdzie należy podjąć najpilniejsze działania mające zapobiec tym niezgodnościom oraz które z tych niezgodności są najistotniejsze, co jest podstawą ustalania działań korygujących. 


\section{Podsumowanie}

W wyniku przeprowadzonej analizy, przy wykorzystaniu diagramu Ishikawy, i diagramu Pareto-Lorenza stwierdzono, że grupy przyczyn, które w największym stopniu mogą wpływać na niezgodności wysięgnika to: człowiek, maszyna, materiał, zarządzanie, metoda, środowisko i pomiar, natomiast najczęściej występującymi niezgodnościami wysięgnika są niedokładny (nierówny) spaw oraz odpadająca powłoka lakiernicza. Z kolei niezgodnościami, które uzyskały w metodzie FMEA najwyższą Liczbę Priorytetową Ryzyka są brak otworu w wysięgniku, użycie złych gwintów i szczeliny w spoinie. Należy skupić się nad kontrolą na każdym etapie procesu produkcyjnego, bardzo pomocne mogą się okazać różnego rodzaju czujniki (elementy PokaYoke), które zminimalizują lub nie dopuszczą do popełnienia błędu przez człowieka. Oczywiście, niezbędne stają się zmiany dotyczące pracownika: większa liczba szkoleń na temat obsługi i przeglądów maszyn, połączenie współpracy pracowników działu utrzymania ruchu i operatorów oraz wprowadzenie systemu zgłaszania pomysłów przez pracowników.

\section{LITERATURA:}

1. Borkowski S. 2004. Mierzenie Poziomu Jakości. Publisher WSZiM, Sosnowiec.

2. BORKOWSKI S., 2012. Tradycyjne narzędzia zarzadzania jakościa. Teoria $i$ praktyka. Wydawnictwo SMJiP. Częstochowa.

3. HAMrol A. 2008. Zarządzanie jakościq z przyktadami, wydanie 2. Wydawnictwo PWN. Warszawa.

4. INGALDI M., JAGUSIAK-KociK M. 2014. Nonconformities Analysis During Production of the Car Counter Cases. Chapter 10. W: Machines Operating Conditions. BorKOWSKI S., KrYNKE M. (red.). 
Wyd. Oficyna Wydawnicza Stowarzyszenia Menedżerów Jakości i Produkcji. Częstochowa.

5. Ingaldi M., RoSAK-SzYRockA J., JAGUSIAK-KocIK M. 2012. Service Quality in the Point of the Mass Nutrition. Chapter 1. W: Toyotarity. Quality of Services Assessment According to BOST Method. Monography. Editing and Scientific Elaboration BoRKOWSKI S., INGALDI M. Faculty of Logistics, University of Maribor. Celje.

6. JAGUSIAK-KOCIK M., KNOP K. 2015. Zapewnienie jakości w przedsiębiorstwie produkujacym zabawki. Rozdział 10. W: Toyotaryzm. Identyfikacja ważności czynników w metodzie BOST. BORKOWSKI S., RoSAK-SzYRocKA J. (red.). Wyd. Oficyna Wydawnicza Stowarzyszenia Menedżerów Jakości i Produkcji. Częstochowa.

7. Knop K., JagusiaK M., StasiaK-BetlejewsKa R. 2009. Chapter 12. The Application of ABC and FMEA Method to Define Critical Parts and Subassemblies of Closing Machine Gopak. [In:] Production Engineering. Ed. and Scientific Elaboration BORKOWSKI S., ULEWICZ R. Publisher Novosibirsk State Tech. Univ. Novosibirsk. 